\title{
Identification and enzymic analysis of a novel protein associated with production of hydrogen sulfide and L-serine from L-cysteine in Fusobacterium nucleatum subsp. nucleatum ATCC 25586
}

Correspondence
Yasuo Yoshida
yasuoy@dpc.agu.ac.jp

Received 11 February 2011

Revised 6 April 2011

Accepted 8 April 2011
Yasuo Yoshida, ${ }^{1}$ Kyosuke Suwabe, ${ }^{1,2}$ Keiji Nagano, ${ }^{1}$ Yuichiro Kezuka, ${ }^{3}$ Hirohisa Kato ${ }^{4}$ and Fuminobu Yoshimura ${ }^{1}$

\author{
${ }^{1}$ Department of Microbiology, School of Dentistry, Aichi Gakuin University, Nagoya, Japan \\ ${ }^{2}$ Department of Conservative Dentistry and Oral Rehabilitation, School of Dentistry, Iwate Medical \\ University, Morioka, Japan \\ ${ }^{3}$ Department of Structural Biology, School of Pharmacy, Iwate Medical University, Yahaba, Japan \\ ${ }^{4}$ Department of Pathogenesis and Control of Oral Disease, School of Dentistry, Iwate Medical \\ University, Morioka, Japan
}

\begin{abstract}
A third enzyme that produces hydrogen sulfide from L-cysteine was identified in Fusobacterium nucleatum subsp. nucleatum. The fn 1055 gene was cloned from a cosmid library constructed with genomic DNA of $F$. nucleatum ATCC 25586. Despite the database annotation that the product of $f n 1055$ is a cysteine synthase, reverse-phase HPLC revealed that no L-cysteine was produced in vitro by the purified Fn1055 protein; however, the enzyme did produce L-serine. In addition, a cysteine auxotroph, Escherichia coli NK3, transformed with a plasmid containing the fn1055 gene did not grow without cysteine, which further suggests that Fn1055 does not function as a cysteine synthase. The Michaelis-Menten kinetics $\left(K_{\mathrm{m}}=0.09 \pm 0.001 \mathrm{mM}\right.$ and $k_{\text {cat }}=5.43 \pm 0.64 \mathrm{~s}^{-1}$ ) of the purified enzyme showed that the capacity of Fn1055 to produce hydrogen sulfide was between that of two other enzymes, Fn0625 and Fn1220. Incubation of Fn1055 with L-cysteine resulted in the production of hydrogen sulfide, but not of pyruvate, ammonia or lanthionine, which are all byproducts produced in addition to hydrogen sulfide when Fn0625 or Fn1220 is incubated with L-cysteine. Instead, Fn1055 produced L-serine in its reaction with L-cysteine. Fn1055 produces hydrogen sulfide from L-cysteine by a mechanism that is different from that of Fn0625 or Fn1220.
\end{abstract}

\section{INTRODUCTION}

Hydrogen sulfide $\left(\mathrm{H}_{2} \mathrm{~S}\right)$ is a dominant volatile sulfur compound (VSC) in the human oral cavity, and VSCs are responsible for oral malodour (Tonzetich, 1971). $\mathrm{H}_{2} \mathrm{~S}$ not only causes aesthetic problems, but also has toxic effects on several tissues and host cells (Calenic et al. 2010a, b; Kurzban et al., 1999; Li et al., 2005; Morhart et al., 1970; Ng \& Tonzetich, 1984; Yaegaki et al., 2008; Yang et al., 2004; Yoshida et al., 2002). In addition, the amount of $\mathrm{H}_{2} \mathrm{~S}$ in periodontal pockets is much higher than the levels of this compound (Persson, 1992) normally associated with the aetiology of periodontitis (Ratcliff \& Johnson, 1999).

Abbreviations: GST, glutathione S-transferase; PLP, pyridoxal 5'-phosphate.
$\mathrm{H}_{2} \mathrm{~S}$ in the human oral cavity is produced as a metabolite of oral bacteria. Fusobacterium nucleatum is known to be a primary source of oral $\mathrm{H}_{2} \mathrm{~S}$ (Claesson et al., 1990; Persson et al., 1990; Pianotti et al., 1986). This micro-organism has multiple enzymes that produce $\mathrm{H}_{2} \mathrm{~S}$ from L-cysteine (Persson et al., 1990). Molecular analyses of Fn1220 (Cdl) and Fn0625 (Lcd), which are associated with $\mathrm{H}_{2} \mathrm{~S}$ production in F. nucleatum, have been recently reported (Fukamachi et al., 2002; Yoshida et al., 2010a). Fn1220 and Fn0625 produce $\mathrm{H}_{2} \mathrm{~S}$ in different ways (Yoshida et al., 2010a): the former catalyses a $\beta$-replacement reaction in which two molecules of L-cysteine condense to generate $\mathrm{H}_{2} \mathrm{~S}$ and lanthionine, whereas the latter catalyses $\beta$ elimination of L-cysteine to produce $\mathrm{H}_{2} \mathrm{~S}$, pyruvate and ammonia. Unsurprisingly, there is no significant amino acid sequence homology between these two enzymes. Even though crude enzyme extracts from F. nucleatum ATCC 
25586 include at least three enzymes associated with production of $\mathrm{H}_{2} \mathrm{~S}$ from L-cysteine (Yoshida et al., 2010a), the enzymes other than Fn1220 and Fn0625 remained to be identified.

In this study, a novel gene encoding an $\mathrm{H}_{2} \mathrm{~S}$-producing enzyme was identified using a cosmid library constructed with the genomic DNA of F. nucleatum ATCC 25586. The enzymic properties of the $37 \mathrm{kDa}$ enzyme encoded by the fn1055 gene were studied. While Fn1055 also produced $\mathrm{H}_{2} \mathrm{~S}$ from L-cysteine, it differed from Fn1220 and Fn0625 as it produced L-serine as a byproduct.

\section{METHODS}

Bacterial strains and culture conditions. Bacteria used in this study are listed in Table 1. F. nucleatum subsp. nucleatum ATCC 25586 was grown anaerobically at $37{ }^{\circ} \mathrm{C}$ in Columbia broth (Difco). Escherichia coli strains were grown aerobically in LB medium (Difco), if necessary with $100 \mu \mathrm{g}$ ampicillin $\mathrm{ml}^{-1}$. E. coli NK3 (Noji et al., 1994) was grown in M9-ALT, which is M9 minimal medium (Sambrook et al., 1989) containing $100 \mu \mathrm{g}$ ampicillin $\mathrm{ml}^{-1}, 200 \mu \mathrm{g}$ leucine $\mathrm{ml}^{-1}$ and $200 \mu \mathrm{g}$ tryptophan $\mathrm{ml}^{-1}$.

Preparation of crude enzyme extracts. Crude enzyme extracts of F. nucleatum ATCC 25586 and E. coli transformants were obtained as previously described (Yoshida et al., 2010a). Briefly, each strain was grown to $\mathrm{OD}_{600} \sim 0.8$. The cells harvested from $40 \mathrm{ml}$ of culture were washed three times with PBS $\left(0.12 \mathrm{M} \mathrm{NaCl}, 0.01 \mathrm{M} \mathrm{Na}_{2} \mathrm{HPO}_{4}, 5 \mathrm{mM}\right.$ $\mathrm{KH}_{2} \mathrm{PO}_{4}$, pH 7.5). The cell suspension was lysed by ultrasonication and centrifuged. Protein concentrations were determined using a protein assay reagent (Bio-Rad) with BSA as standard. The samples were stored at $-20{ }^{\circ} \mathrm{C}$ after adding an equal volume of $80 \%(\mathrm{v} / \mathrm{v})$ glycerol.

Visualization of enzymic activity. The activity of crude or purified enzymes that produced $\mathrm{H}_{2} \mathrm{~S}$ from L-cysteine was visualized using SDS-PAGE with renaturation to remove the reducing/denaturing agent, followed by active staining, as previously described (Yoshida et al., 2010b). Briefly, protein samples (20 $\mu \mathrm{g}$ for crude enzyme extracts and $2 \mu \mathrm{g}$ for purified enzyme) were electrophoresed at $20 \mathrm{~mA}$ per gel at $4{ }^{\circ} \mathrm{C}$ on $12.5 \%(\mathrm{w} / \mathrm{v})$ polyacrylamide gels $(\mathrm{pH} 8.8)$ with
$0.1 \%$ SDS. The gels were renatured slowly in buffer by replacement of SDS with the detergents Triton X-100 and Lubrol PX so that the gels were shifted from noncatalytic to catalytic conditions. The gels were incubated in $10 \mathrm{ml}$ of a visualizing solution [100 $\mathrm{mM}$ triethanolamine- $\mathrm{HCl}, \mathrm{pH} 7.6,10 \mu \mathrm{M}$ pyridoxal $5^{\prime}$-phosphate (PLP), $0.5 \mathrm{mM}$ bismuth trichloride, $10 \mathrm{mM}$ EDTA, $5.0 \mathrm{mM}$ L-cysteine] at $37{ }^{\circ} \mathrm{C}$. The enzyme was detected as a black band with the appropriate apparent molecular mass (Claesson et al., 1990).

Cloning of the gene encoding the $\mathrm{H}_{2} \mathrm{~S}$-producing enzyme. A cosmid gene bank of $F$. nucleatum ATCC 25586 was constructed as follows. After the chromosomal DNA of the strain had been partially digested with ApoI, approximately 5-15 kb fragments were obtained using sucrose density gradient ultracentrifugation $(65000 \mathrm{~g})$, ligated with the $36 \mathrm{~kb}$ cosmid vector Charomid 9-36 (Nippon Gene) previously digested with EcoRI, packaged into bacteriophage $\lambda$ (Gigapack III Gold Packaging Extracts, Stratagene), and then transfected into E. coli LC815, a mutant strain with a low capacity to produce $\mathrm{H}_{2} \mathrm{~S}$ from L-cysteine in a low-pH environment (Fukamachi et al., 2002).

Approximately 2500 colonies in the cosmid gene bank were grown on $2 \times$ TY plates, transferred to a nitrocellulose membrane, and soaked in visualizing solution as described above. The $\mathrm{H}_{2} \mathrm{~S}$-producing colonies were dark brown.

Plasmids to produce recombinant proteins. Plasmids (Table 1) for production of proteins fused with glutathione $S$-transferase (GST) were constructed using the expression vector pGEX-6P-1 (GE Healthcare), as previously described (Yoshida et al., 2002). Briefly, each entire gene was PCR-amplified with primers designed to incorporate a BamHI site at the $5^{\prime}$ end and a Sali site at the $3^{\prime}$ end of each segment. After PCR amplification, the reaction products were digested with BamHI and SalI and ligated into pGEX-6P-1, juxtaposing the gene fragment downstream from the coding sequence for GST and a PreScission protease cleavage site to yield pGEX6p-1fn1055.

Purification of recombinant proteins. To purify the $f n 1055$ protein product, pGEX6p-1-fn1055 was transformed into E. coli BL21, which was grown to $\mathrm{OD}_{600} 0.7$ at $37{ }^{\circ} \mathrm{C}$, and 0.21 cultures were induced with $0.3 \mathrm{mM} \mathrm{IPTG}$ for $2 \mathrm{~h}$. Cells were centrifuged at $5000 \mathrm{~g}$, resuspended in $20 \mathrm{ml} \mathrm{PBS}$, and then sonicated. Cell debris was removed by centrifugation at $20000 \mathrm{~g}$ and $4{ }^{\circ} \mathrm{C}$. The supernatant was loaded onto a $1 \mathrm{ml}$ glutathione Sepharose 4B (GE Healthcare)

Table 1. Strains and plasmids used in this study

\begin{tabular}{|c|c|c|}
\hline Strain or plasmid & Description & Source or reference \\
\hline \multicolumn{3}{|l|}{ Strains } \\
\hline $\begin{array}{l}\text { F. nucleatum subsp. nucleatum } \\
\text { ATCC } 25586\end{array}$ & Isolate from a cervico-facial lesion & $\begin{array}{l}\text { RIKEN BioResource Center, } \\
\text { Wako, Japan }\end{array}$ \\
\hline E. coli $\mathrm{DH} 5 \alpha$ & $\mathrm{F}^{-}$endA1 hsdR17 $\left(\mathrm{r}_{\mathrm{K}}^{-} \mathrm{m}_{\mathrm{K}}^{+}\right)$supE44 thi-1 recA1 gyrA96 p80lacZM15 & Invitrogen \\
\hline E. coli BL21 & $\mathrm{F}^{-}$ompT $h s d S_{B}\left(\mathrm{r}_{\mathrm{B}}^{-} \mathrm{m}_{\mathrm{B}}^{-}\right)$gal dcm rne131 & Novagen \\
\hline E. coli LC815 & Mutant strain with a low activity for $\mathrm{H}_{2} \mathrm{~S}$ production & Fukamachi et al. (2002) \\
\hline \multicolumn{3}{|l|}{ Plasmids } \\
\hline pGEX6P-1 & Cloning vector & GE Healthcare \\
\hline pGEX6p-1-cysM & Production of GST-CysM of E. coli K-12 & This study \\
\hline pGEX6p-1-cysK & Production of GST-CysK of E. coli $\mathrm{K}-12$ & This study \\
\hline pGEX6p-1-fn0625 & Production of GST-Fn0625 of F. nucleatum ATCC 25586 & Yoshida et al. (2010a) \\
\hline pGEX6p-1-fn1055 & Production of GST-Fn1055 of F. nucleatum ATCC 25586 & This study \\
\hline
\end{tabular}


column equilibrated with PBS. The resin was washed with PBS, equilibrated with PreScission protease buffer $(50 \mathrm{mM}$ Tris/ $\mathrm{HCl}$, $\mathrm{pH}$ 7.0, $150 \mathrm{mM} \mathrm{NaCl}, 1 \mathrm{mM}$ EDTA, $1 \mathrm{mM}$ DTT), and incubated with $80 \mathrm{U}$ PreScission protease (GE Healthcare) for $12 \mathrm{~h}$ at $4{ }^{\circ} \mathrm{C}$. The enzyme was eluted in $2 \mathrm{ml}$ PreScission protease buffer. GST and PreScission protease remain bound to the beads in this procedure. The eluate was loaded onto a prepacked anion exchange column (HiTrap Q HP, GE Healthcare), a linear $\mathrm{NaCl}$ gradient $(0.1-0.6 \mathrm{M})$ in $20 \mathrm{mM}$ Tris/ $\mathrm{HCl}$ buffer, $\mathrm{pH} 8.5$, was used for elution at a flow rate of $0.5 \mathrm{ml} \mathrm{m^{-1 }}$ at $4{ }^{\circ} \mathrm{C}$, and $1.0 \mathrm{ml}$ fractions were collected. The enzyme samples were stored at $-20{ }^{\circ} \mathrm{C}$ after adding an equal volume of $80 \%(\mathrm{v} / \mathrm{v})$ glycerol. The protein concentrations were determined as described by Pace et al. (1995). The purity of the protein samples was assessed by SDS-PAGE.

The Fn0625 and Fn1220 proteins were prepared as described previously (Yoshida et al., 2010a), and were further purified using the anion exchange HiTrap Q HP column described above.

Gel-filtration chromatography. The molecular mass of the purified Fn1055 proteins was determined by gel-filtration chromatography with a Superdex $200 \mathrm{HR} 10 / 30$ column (GE Healthcare) at a flow rate of $0.25 \mathrm{ml} \mathrm{min} \mathrm{min}^{-1}$ in PBS. A standard curve was produced by gel filtration of molecular mass standards (kit for molecular weights $43000-158000$, GE Healthcare). Enzyme elution was monitored at $280 \mathrm{~nm}$. At least two independent experiments were performed, and a representative chromatogram is shown.

Enzyme assay. The enzymic activity of the purified proteins was assessed using a modification of the method of Schmidt (1987), which measures the production of $\mathrm{H}_{2} \mathrm{~S}$ from L-cysteine. Briefly, the reaction mixture $(100 \mu \mathrm{l})$ contained $40 \mathrm{mM}$ potassium phosphate buffer ( $\mathrm{pH}$ 7.6), $10 \mu \mathrm{M}$ PLP, the purified enzyme (Fn1055, $159.5 \mathrm{ng}$; Fn1220, $101 \mathrm{ng}$; Fn0625, $4.65 \mu \mathrm{g}$ ), and various concentrations of substrate(s). The reaction $(100 \mu \mathrm{l})$ was incubated at $37{ }^{\circ} \mathrm{C}$ for $2 \mathrm{~min}$, and terminated by the addition of $20 \mu$ l termination buffer, which was freshly prepared by mixing $10 \mu \mathrm{l}$ solution I $\left(20 \mathrm{mM} N^{\prime}, N^{\prime}\right.$ dimethyl- $p$-phenylenediamine dihydrochloride in $7.2 \mathrm{M} \mathrm{HCl}$ ) and $10 \mu$ solution II $\left(30 \mathrm{mM} \mathrm{FeCl}_{3}\right.$ in $\left.1.2 \mathrm{M} \mathrm{HCl}\right)$. After incubation for $30 \mathrm{~min}$ at room temperature, methylene blue formation was measured spectrophotometrically at $670 \mathrm{~nm}$ alongside a standard curve. The standard curve was prepared using $\beta \mathrm{C}$-S lyase from Streptococcus anginosus IMU102, which produces equal amounts of pyruvate and $\mathrm{H}_{2} \mathrm{~S}$ from L-cysteine (Ito et al., 2008).

Kinetic parameters were computed from the Lineweaver-Burk transformation of the Michaelis-Menten equation. The $k_{\text {cat }}$ values were calculated using the $V_{\max }$ values and the molecular masses of the enzymes.

The formation of ammonia as an end product was determined using


manufacturer's protocols.

Gas chromatography. Gas chromatography was performed as previously described (Yoshida et al., 2010a) to detect sulfur compounds, including $\mathrm{H}_{2} \mathrm{~S}$, methylmercaptan and ethylmercaptan (ethanethiol), which were predicted to be byproducts formed upon $\beta$ - or $\gamma$-elimination of specific substrates. The reaction mixture $(100 \mu \mathrm{l})$ contained $20 \mu \mathrm{g}$ recombinant protein, $10 \mathrm{mM}$ substrate, $10 \mu \mathrm{M}$ PLP and $40 \mathrm{mM}$ potassium phosphate buffer $(\mathrm{pH} 7.6)$. The reaction mixture was prepared in a $10 \mathrm{ml}$ glass tube, sealed with a silicone plug, and incubated at $37{ }^{\circ} \mathrm{C}$ for $10 \mathrm{~min}$. A sample $(1 \mathrm{ml})$ of the vapour above the reaction mixture was removed with a gas-tight syringe, without removing the silicone plug, and analysed by gas chromatography (model GC-8A, Shimadzu) using a Teflon column packed with $20 \% \beta, \beta^{\prime}$-oxydipropionitrile on an 80-100 mesh Chromosorb W AW-DMCS-ST device (Shimadzu) fitted with a flame photometric detector at $70{ }^{\circ} \mathrm{C}$.
HPLC. The production of serine, homoserine, homocysteine and 2aminoethanethiol, which were predicted to be products of Fn1055, was assessed using a reverse-phase HPLC column. The reaction mixtures contained the following reagents in a final volume of $100 \mu \mathrm{l}$ : $40 \mathrm{mM}$ potassium phosphate buffer ( $\mathrm{pH} 8.5$ ), $10 \mu \mathrm{M}$ PLP, $5 \mathrm{mM}$ substrate(s) and $2.5 \mu \mathrm{g}$ purified enzyme. After the mixtures had incubated for $2.5 \mathrm{~h}$ at $37{ }^{\circ} \mathrm{C}$, the enzymes were removed using a Microcon YM-10 filter (10 kDa cut-off, Amicon). The ultrafiltration products were dansylated as described by Tapuhi et al. (1981). Aliquots $(20 \mu \mathrm{l})$ of each sample were applied to an XTerra $\mathrm{RP}_{18}$ column by injection $(4.6 \times 150 \mathrm{~mm}$, Waters $)$. The dansylated products were separated at a flow rate of 1.0 or $0.5 \mathrm{ml} \mathrm{min}{ }^{-1}$ at $40{ }^{\circ} \mathrm{C}$ with a mobile phase of $33.25 / 66.75(\mathrm{v} / \mathrm{v})$ methanol/water containing $0.6 \%(\mathrm{v} / \mathrm{v})$ glacial acetic acid and $0.008 \%(\mathrm{v} / \mathrm{v})$ triethylamine. Excitation and emission wavelengths were 350 and $530 \mathrm{~nm}$, respectively. At least two independent experiments were performed, and representative chromatograms are shown.

Growth test using the cysteine auxotroph E. coli NK3. The cysteine auxotroph E. coli NK3 was transformed with the plasmids listed in Table 1. The transformants grown in LB broth for $24 \mathrm{~h}$ were washed three times with M9-ALT, plated on M9-ALT agar, and then incubated for $18 \mathrm{~h}$.

\section{RESULTS}

\section{Cloning of fn1055, encoding a new enzyme associated with $\mathrm{H}_{2} \mathrm{~S}$ production}

Previous results (Yoshida et al., 2010b) showed that crude enzyme extracts from each of five subspecies of $F$. nucleatum contained multiple $\mathrm{H}_{2} \mathrm{~S}$-producing enzymes. These included Fn0625 and Fn1220, which have been characterized previously (Fukamachi et al., 2002; Yoshida et al., 2010a). To identify additional enzymes that produce $\mathrm{H}_{2} \mathrm{~S}$ from L-cysteine, a cosmid library was constructed with the genomic DNA of F. nucleatum ATCC 25586. Of 2500 colonies tested, seven that produced $\mathrm{H}_{2} \mathrm{~S}$ were identified by their brown colour in the visualizing solution. PCR analysis resulted in amplification of $f n 1220$ from four positive colonies, but neither fn1220 nor fn0625 was detected in the remaining three colonies. Since those three cosmid DNAs had identical restriction enzyme fingerprinting profiles, one representative cosmid designated pLC10-1-21 was used for analysis. Activity staining analysis combined with SDSPAGE, which was followed by renaturation, confirmed that the crude enzyme extracts from $E$. coli harbouring pLC101-21 contained one protein band associated with $\mathrm{H}_{2} \mathrm{~S}$ production (Fig. 1a, lane 3). This indicated that pLC10-121 contained a gene encoding an $\mathrm{H}_{2} \mathrm{~S}$-producing protein.

DNA sequence analysis showed that pLC10-1-21 contained a $10 \mathrm{~kb}$ DNA fragment with the $f n 1055$ gene that encodes a putative cysteine synthase (Kapatral et al., 2002). No other genes predicted to be associated with the assimilation and catabolism of sulfur-containing molecules were identified within that DNA. The amino acid sequence of the Fn 1055 protein showed 30 and $32 \%$ identity with that of E. coli CysM and CysK, respectively. Both of these enzymes synthesize L-cysteine from $\mathrm{O}$-acetylserine and sulfide (Kredich, 1996). Fn1055 also showed amino acid sequence 
(a) CBB staining Activity staining

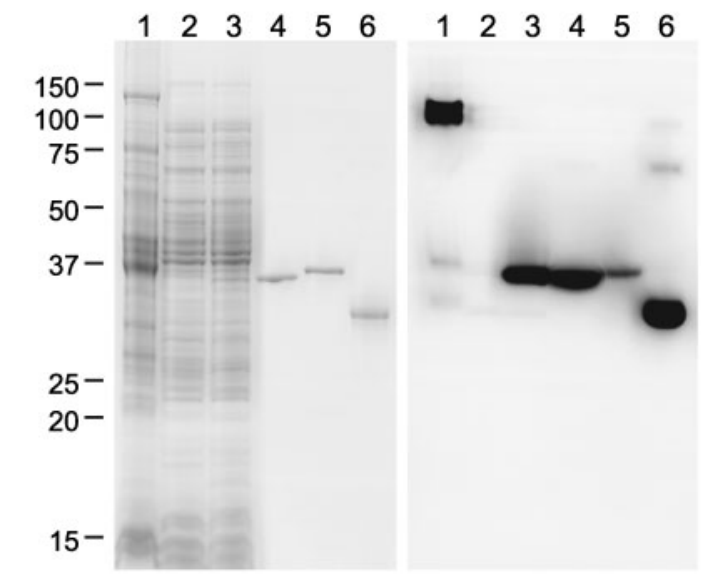

(b)
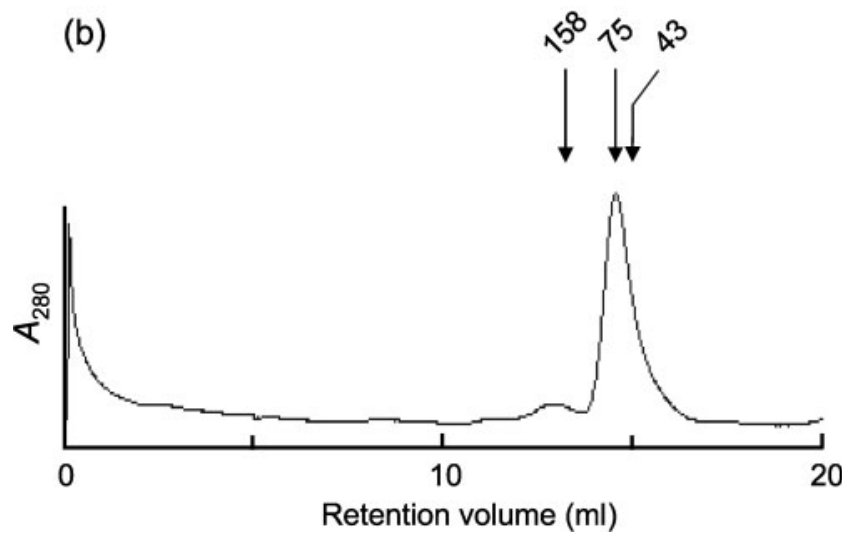

Fig. 1. Analysis of crude enzyme extracts and purified proteins of $F$. nucleatum ATCC 25586. (a) SDS-PAGE analysis. Left panel, gel stained with Coomassie brilliant blue; right panel, after the gel was renatured (see Methods), the enzymic activity to produce $\mathrm{H}_{2} \mathrm{~S}$ was visualized by active staining. Lanes: 1 , cell lysate from $F$. nucleatum subsp. nucleatum ATCC 25586; 2, cell lysate from E. coli LC815 harbouring a cosmid vector, charomid 9-36 (negative control); 3 , cell lysate from $E$. coli LC815 harbouring pLC10-1-21; 4, purified Fn1055 of $F$. nucleatum subsp. nucleatum ATCC 25586; 5 , purified Fn0625 of $F$. nucleatum subsp. nucleatum ATCC 25586; 6, purified Fn1220 of $F$. nucleatum subsp. nucleatum ATCC 25586. The amounts of crude and purified proteins applied to the gel were 20 and $1 \mu \mathrm{g}$, respectively. The value for each molecular mass marker is given in $\mathrm{kDa}$. (b) Gel-filtration chromatography of purified Fn1055 on Superdex 200 HR10/30. The elution volumes of molecular mass standards (158 kDa, aldolase; $75 \mathrm{kDa}$, conalbumin; $43 \mathrm{kDa}$ ovalbumin) are indicated by arrows.

identity (33\%) with Fn1220 but not with Fn0625 in F. nucleatum ATCC 25586 (Yoshida et al., 2010a).

\section{Purification and characterization of Fn1055}

To evaluate the enzymic activity of Fn1055, the recombinant protein was purified (Fig. la, lane 4). The molecular mass of the denatured polypeptide was approximately
$37 \mathrm{kDa}$, which agreed with the predicted molecular mass $(37.3 \mathrm{kDa})$. Gel-filtration chromatography showed that the purified Fn1055 was eluted at retention volumes corresponding to $75 \mathrm{kDa}$ conalbumin (Fig. 1b), suggesting that Fn1055 protein may exist as a homodimer in solution. Activity staining analysis (Fig. 1a) showed that the purified Fn1055 protein (lane 4) produced $\mathrm{H}_{2} \mathrm{~S}$ from L-cysteine. Furthermore, the electrophoretic migration of the recombinant protein agreed with that observed for the $\mathrm{H}_{2} \mathrm{~S}$ producing protein found in the crude enzyme extracts from E. coli that harboured pLC10-1-21 (lane 3).

\section{Fn1055 produces serine from cysteine}

Gas chromatography analysis confirmed that incubation of recombinant Fn1055 with L-cysteine yielded $\mathrm{H}_{2} \mathrm{~S}$ (data not shown). Spectrophotometric analyses did not identify the presence of pyruvate or ammonia, which are produced as byproducts in the reaction of Fn0625 with L-cysteine. Furthermore, HPLC analysis did not detect lanthionine, a byproduct of the reaction of Fn1220 with L-cysteine. These results suggested that Fn1055 might convert L-cysteine to L-serine and $\mathrm{H}_{2} \mathrm{~S}$. HPLC analysis demonstrated that the reaction of Fn1055 with dansylated L-cysteine yielded dansylated L-serine (Fig. 2).

\section{Kinetic properties of Fn1055}

A spectrophotometric assay that measured the production of $\mathrm{H}_{2} \mathrm{~S}$ in the presence of $\mathrm{L}$-cysteine was used to determine

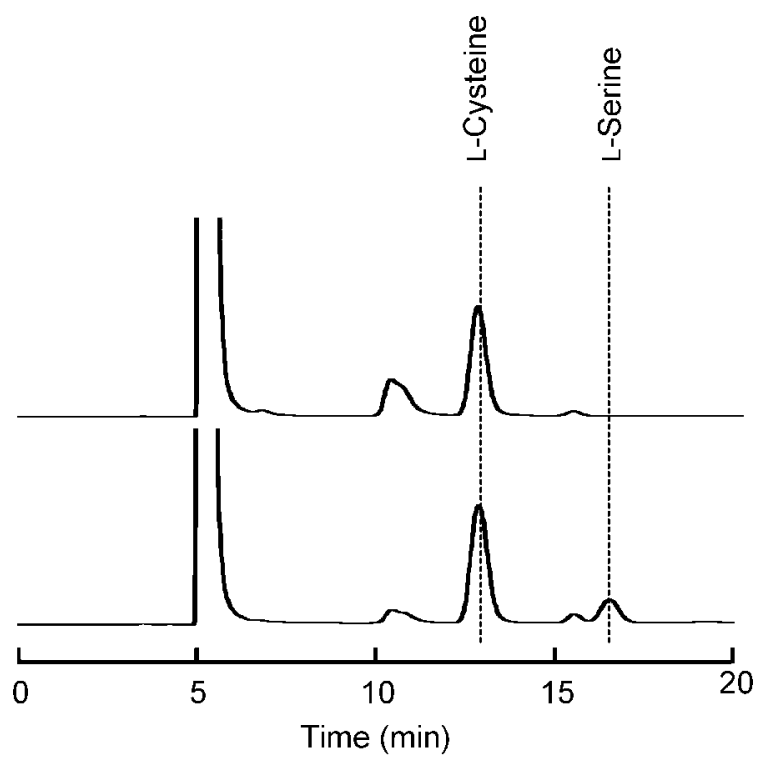

Fig. 2. Reverse-phase HPLC analysis of Fn1055 reaction products. Dansylated reaction products were detected using excitation and emission wavelengths of 350 and $530 \mathrm{~nm}$, respectively. Top panel, reaction products obtained without Fn1055 (negative control); bottom panel, reaction products obtained with purified Fn1055. Peaks were identified by retention time. 
Table 2. Kinetic properties of Fn1055, Fn0625 and Fn1220 from F. nucleatum ATCC 25586

\begin{tabular}{|llcc|}
\hline Enzyme & \multicolumn{1}{c}{ End products } & $\boldsymbol{K}_{\mathbf{m}}(\mathbf{m M})$ & $\boldsymbol{k}_{\text {cat }}\left(\mathbf{s}^{-\mathbf{1}}\right)$ \\
\hline Fn1055 & $\mathrm{H}_{2} \mathrm{~S}$, serine & $0.09 \pm 0.001$ & $5.43 \pm 0.64$ \\
Fn0625 & $\mathrm{H}_{2} \mathrm{~S}$, ammonia, pyruvate & $0.152 \pm 0.017$ & $0.092 \pm 0.009$ \\
Fn1220 & $\mathrm{H}_{2} \mathrm{~S}$, lanthionine & $0.156 \pm 0.012$ & $17.07 \pm 0.941$ \\
\hline
\end{tabular}

the activities of the purified Fn1055, Fn0625 and Fn1220 proteins (Table 2). The $K_{\mathrm{m}}$ value for Fn1055 was lower than the values determined for Fn0625 and Fn1220, suggesting that Fn1055 has a higher affinity for L-cysteine. By contrast, the $k_{\text {cat }}$ value for Fn1055 was lower than that for Fn1220, but was higher than that for Fn0625. To evaluate the enzymic properties of Fn1055, several sulfurcontaining molecules were tested for $\beta$ - and $\gamma$-elimination (Table 3). With the exception of L-cysteine, none of the molecules listed in Table 3 was a substrate for Fn1055.

\section{Fn1055 does not promote synthesis of cysteine}

Two assays were used to determine whether Fn1055 promotes synthesis of L-cysteine. First, unlike CysK and CysM in E. coli (Sirko et al., 1987; Wiater \& Hulanicka, 1979), Fn1055 did not produce L-cysteine from Oacetylserine and NaHS (Fig. 3a). Second, incubation of Fn1055 with L-serine and NaHS did not yield L-cysteine (data not shown). Furthermore, the cysteine auxotroph $E$. coli NK was transformed with pGEX6p-1-fn1055 (Table 1), which encoded a fusion protein of GST and Fn1055. The transformant did not grow on M9 minimal medium without L-cysteine, which provided additional evidence that Fn1055 does not catalyse biosynthesis of L-cysteine. E. coli NK3 did not grow in the absence of L-cysteine (Fig. 3b) when transformed with pGEX6p-1-fn0625 or pGEX6p-1fn1220 (Table 1), but it grew well when transformed with either pGEX6p-1-cysM or pGEX6p-1-cysK.

\section{DISCUSSION}

F. nucleatum has a high $\mathrm{H}_{2} \mathrm{~S}$-producing activity (Persson et al., 1990). Five subspecies of F. nucleatum (i.e. nucleatum, vincentii, polymorphum, fusiforme and animalis) each contain multiple enzymes that produce $\mathrm{H}_{2} \mathrm{~S}$ from L-cysteine (Yoshida et al., 2010b), and two of these $\mathrm{H}_{2} \mathrm{~S}$ producing enzymes (i.e. Fn0625 and Fn1220) have been characterized (Yoshida et al., 2010a). The current study of $F$. nucleatum subsp. nucleatum identified Fn1055 as another $\mathrm{H}_{2} \mathrm{~S}$-producing enzyme.

Of seven $\mathrm{H}_{2} \mathrm{~S}$-producing colonies identified from the cosmid library constructed with the genomic DNA of $F$. nucleatum ATCC 25586, three carried the fn1055 gene, whereas the remaining four carried the $f n 1220$ gene. No colonies carrying the fn0625 gene were isolated, probably because the $\mathrm{H}_{2} \mathrm{~S}$-producing activity of Fn0625 is much lower than those of Fn1055 and Fn1220 (Table 2). We also found no colonies containing other $\mathrm{H}_{2} \mathrm{~S}$-producing proteins, including the approximately $130 \mathrm{kDa}$ protein, which seemed to have the highest activity to produce $\mathrm{H}_{2} \mathrm{~S}$ in the crude enzyme extracts of $F$. nucleatum ATCC 25586 (Fig. 1b). It would be of interest to identify and characterize this protein, which was observed to be common to five subspecies of F. nucleatum (Yoshida et al., 2010b).

The $K_{\mathrm{m}}$ of Fn1055 was the lowest among the three $\mathrm{H}_{2} \mathrm{~S}$ producing enzymes in F. nucleatum ATCC 25586, suggesting that Fn1055 has the highest affinity for L-cysteine (Table 2). By contrast, the $k_{\text {cat }}$ value of Fn1055 was approximately one-third of that found for Fn1220, but was much higher than that found for Fn0625. Previously reported kinetic values for Fn0625 and Fn1220 (Yoshida et al., 2010a) were different from those determined in this study (Table 2). The discrepancy might be caused by differences in methods of enzyme purification and spectrophotometric assays. In the current study, an anionexchange column and a GST affinity column were used to obtain more highly purified enzymes, while in the

Table 3. Potential elimination reactions catalysed by Fn1055 from F. nucleatum ATCC 25586

\begin{tabular}{|c|c|c|c|c|c|}
\hline \multirow[t]{2}{*}{ Reaction } & \multirow[t]{2}{*}{ Substrate } & \multicolumn{4}{|c|}{$\beta$ - or $\gamma$-Elimination reaction } \\
\hline & & Elimination & \multicolumn{2}{|c|}{ Predicted end products } & \multirow{2}{*}{$\begin{array}{c}\begin{array}{r}\text { Catalysed } \\
\text { by Fn1055 }\end{array} \\
\text { Yes }\end{array}$} \\
\hline 1 & L-Cysteine & $\beta$ & Serine $^{*}$ & $\mathrm{H}_{2} \mathrm{~S} \dagger$ & \\
\hline 2 & L-Cystathionine & $\beta$ & Serine & Homocysteine $^{\star}$ & No \\
\hline 3 & S-(2-Aminoethyl)-L-cysteine & $\beta$ & Serine & $\begin{array}{l}\text { 2-Aminoethanethiol } \\
{\text { (cysteamine })^{*}}^{\text {(c) }}\end{array}$ & No \\
\hline 4 & S-Methyl-L-cysteine & $\beta$ & Serine & Methylmercaptan $\dagger$ & No \\
\hline 5 & $S$-Ethyl-L-cysteine & $\beta$ & Serine & $\begin{array}{l}\text { Ethylmercaptan } \dagger \\
\text { (ethanethiol) }\end{array}$ & No \\
\hline 6 & Methionine & $\gamma$ & Homoserine ${ }^{\star}$ & Methylmercaptan $\dagger$ & No \\
\hline
\end{tabular}

${ }^{\star}$ Determined by HPLC.

$\dagger$ Determined by gas chromatography. 
(a)

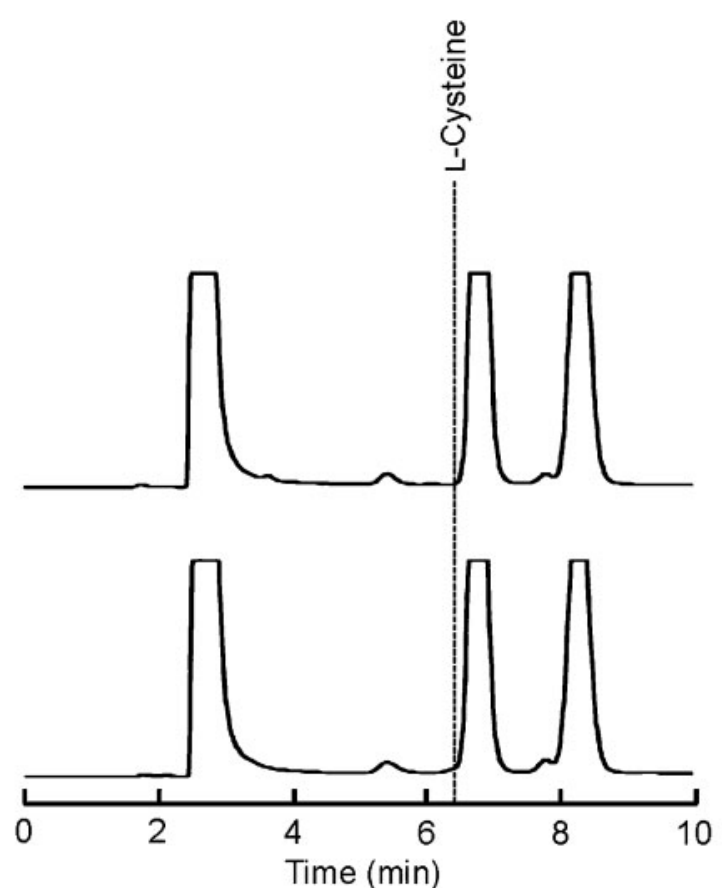

(b)

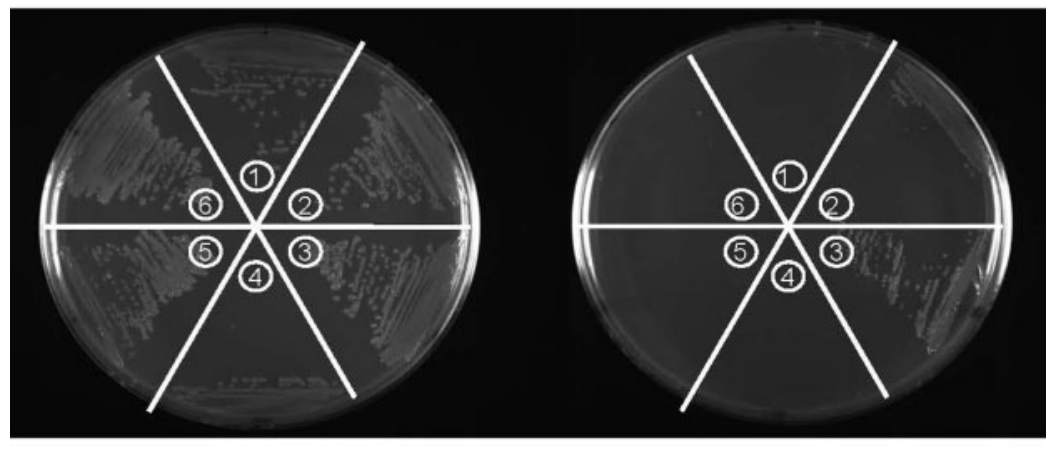

Cysteine (+)
Cysteine (-)
Fig. 3. Fn1055 is not a cysteine synthase. (a) Reverse-phase HPLC analysis for L-cysteine in the reactions of $\mathrm{O}$-acetyl-L-serine and $\mathrm{NaHS}$ with purified Fn1055. Top panel, reaction products obtained without Fn1055 (negative control); bottom panel, reaction products obtained with purified Fn1055. (b) Genetic complementation analysis of the cysteine auxotroph E. coli NK3, which was transformed with (1) pGEX-6p-1 (negative control), (2) pGEX-6p-1-cysM, (3) pGEX-6p-1-cysK, (4) pGEX-6p-1-fn0625, (5) pGEX-6p-1-fn1055 and (6) pGEX-6p-1-fn1220. The transformants were spread on M9 minimal agar plates supplemented with $100 \mu \mathrm{g}$ ampicillin $\mathrm{ml}^{-1}$, $200 \mu \mathrm{g}$ leucine $\mathrm{ml}^{-1}$ and $100 \mu \mathrm{g}$ tryptophan $\mathrm{ml}^{-1}$, with or without $0.5 \mathrm{mM}$ L-cysteine. previous study only the GST affinity column was used. In addition, the original method to measure $\mathrm{H}_{2} \mathrm{~S}$ using methylene blue was modified for the present study. In previous studies, the terminating and developing solutions were added to the reaction mixtures separately (Yoshida et al., 2010a). In this study, the two solutions were added at the same time, which allowed the $\mathrm{H}_{2} \mathrm{~S}$ produced to react completely with the reagent. Thus, the kinetic measurements of Fn0625 and Fn1220 might be more precise here than in earlier studies.

In E. coli and several other micro-organisms, L-serine is biosynthesized from the glycolytic intermediate 3-phosphoglycerate by sequential reactions of 3-phosphoglycerate dehydrogenase, phosphoserine aminotransferase and phosphoserine phosphatase. Interestingly, a database analysis showed that the genomic DNA of F. nucleatum ATCC 25586 does not contain any homologous genes that encode these enzymes. However, as shown in this study, L-serine was produced in the reaction of Fn1055 with L-cysteine. Although it is not known whether $\beta$-elimination of L-cysteine is the only pathway to produce L-serine in $F$. nucleatum, the biosynthetic pathways of amino acids, including L-serine, seem to be different from those reported in E. coli and other bacteria. Further investigation is necessary to understand the assimilation and catabolism of amino acids in F. nucleatum.

Three F. nucleatum enzymes (i.e. Fn1055, Fn0625 and Fn1220), all of which form homodimers in solution (Yoshida et al., 2010a), are associated with $\mathrm{H}_{2} \mathrm{~S}$ production from L-cysteine, but all have distinct mechanisms. Considering the bacterial pathways for $\mathrm{H}_{2} \mathrm{~S}$ production, most reactions reported so far involve $\alpha, \beta$-elimination of L-cysteine, in which pyruvate and ammonia are produced together with $\mathrm{H}_{2} \mathrm{~S}$. This reaction is associated with the Fn0625 protein in F. nucleatum (Fig. 4). Other bacterial pathways that produce $\mathrm{H}_{2} \mathrm{~S}$ have only recently been 
Fn01055

: $\beta$-Elimination

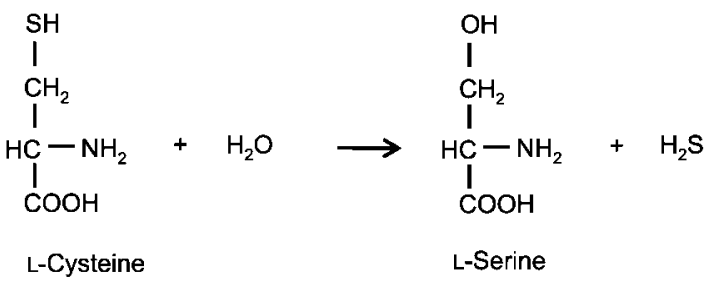

$\alpha, \beta$-Elimination

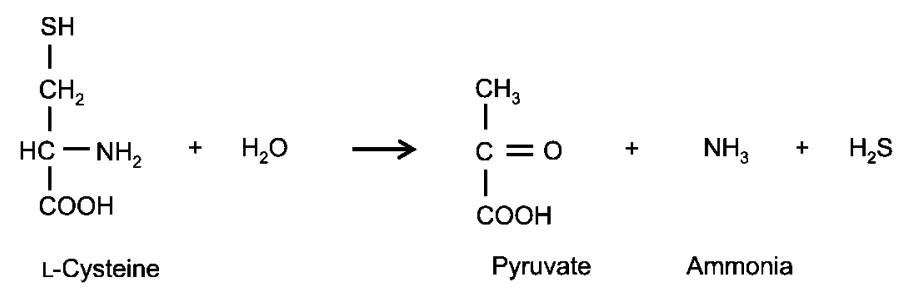

Fn1220

ß-Replacement

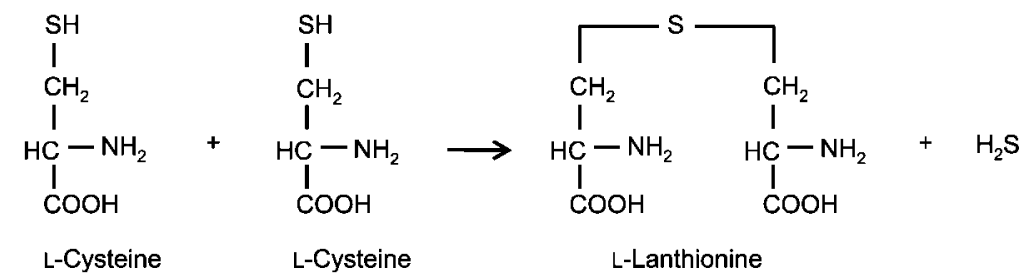

Fig. 4. Reactions catalysed by Fn1055, Fn0625 and Fn1220.

reported (Yoshida et al., 2010a), and involve $\beta$-replacement of L-cysteine catalysed by Fn1220 (Fig. 4). Thus, $\beta$ elimination to produce $\mathrm{H}_{2} \mathrm{~S}$ and serine from L-cysteine may be a novel finding in bacteria. By contrast, human cystathionine $\beta$-synthase (CBS), which converts L-serine and homocysteine to L-cystathionine, also catalyses $\beta$ elimination of L-cysteine to produce L-serine and $\mathrm{H}_{2} \mathrm{~S}$ as well as $\beta$-replacement of L-cysteine to produce L-lanthionine and $\mathrm{H}_{2} \mathrm{~S}$ (Singh et al., 2009). In F. nucleatum, the former reaction was catalysed by Fn 1055 whereas the latter reaction was catalysed by Fn1220. However, the CBS turnover number for serine production is approximately $3 \%$ of that found for cystathionine biosynthesis, suggesting that degradation of L-cysteine by CBS might be an incidental reaction due to its broad substrate specificity.

It is not known why $\mathrm{H}_{2} \mathrm{~S}$ production is mediated by three different enzymes in F. nucleatum. The capacity of Fn0625 to produce L-homocysteine from L-cystathionine is much higher than its capacity to produce $\mathrm{H}_{2} \mathrm{~S}$ from L-cysteine (Yoshida et al., 2010a). Since L-homocysteine is an intermediate in the L-methionine biosynthetic pathway, Fn0625 may be important in terms of L-methionine biosynthesis. In contrast, the substrate specificities of
Fn1055 and Fn1220 seem to be limited to L-cysteine only (Yoshida et al., 2010a). The byproducts (i.e. L-serine and L-lanthionine) in the reaction of the proteins with L-cysteine might be more important in F. nucleatum. Indeed, lanthionine is a natural constituent of the peptidoglycans isolated from F. nucleatum (Kato et al., 1979).

In conclusion, a third enzyme (Fn1055) associated with $\mathrm{H}_{2} \mathrm{~S}$ production in $F$. nucleatum was identified and characterized. The mechanism used to produce $\mathrm{H}_{2} \mathrm{~S}$ from L-cysteine was found to be different from those of previously characterized enzymes. However, the approximately $130 \mathrm{kDa}$ protein showing the highest activity to produce $\mathrm{H}_{2} \mathrm{~S}$ from L-cysteine in the crude enzyme extracts of F. nucleatum ATCC 25586 has not been elucidated. Further studies are necessary to understand the mechanism of $\mathrm{H}_{2} \mathrm{~S}$ production in $\mathrm{F}$. nucleatum.

\section{ACKNOWLEDGEMENTS}

We thank Dr Yoshio Nakano of Nihon University (Tokyo, Japan) and Dr Kazuki Saito of Chiba University (Chiba, Japan) for providing $E$. coli strains LC815 and NK3, respectively. This study was supported in part by Grants-in-Aid for Scientific Research (nos 20592463 and 
20592181) and by the Strategic Medical Research Center of the Ministry of Education, Culture, Sports, Science and Technology, Japan. This work is dedicated to people in the Iwate prefecture who lost their lives in the earthquake and tsunami on 11 March 2011.

\section{REFERENCES}

Calenic, B., Yaegaki, K., Kozhuharova, A. \& Imai, T. (2010a). Oral malodorous compound causes oxidative stress and p53-mediated programmed cell death in keratinocyte stem cells. J Periodontol 81, 1317-1323.

Calenic, B., Yaegaki, K., Murata, T., Imai, T., Aoyama, I., Sato, T. \& li, H. (2010b). Oral malodorous compound triggers mitochondrialdependent apoptosis and causes genomic DNA damage in human gingival epithelial cells. J Periodontal Res 45, 31-37.

Claesson, R., Edlund, M. B., Persson, S. \& Carlsson, J. (1990). Production of volatile sulfur compounds by various Fusobacterium species. Oral Microbiol Immunol 5, 137-142.

Fukamachi, H., Nakano, Y., Yoshimura, M. \& Koga, T. (2002). Cloning and characterization of the L-cysteine desulfhydrase gene of Fusobacterium nucleatum. FEMS Microbiol Lett 215, 75-80.

Ito, S., Nagamune, H., Tamura, H. \& Yoshida, Y. (2008). Identification and molecular analysis of $\beta \mathrm{C}$-S lyase producing hydrogen sulfide in Streptococcus intermedius. J Med Microbiol 57, 1411-1419.

Kapatral, V., Anderson, I., Ivanova, N., Reznik, G., Los, T., Lykidis, A., Bhattacharyya, A., Bartman, A., Gardner, W. \& other authors (2002). Genome sequence and analysis of the oral bacterium Fusobacterium nucleatum strain ATCC 25586. J Bacteriol 184, 2005-2018.

Kato, K., Umemoto, T., Sagawa, H. \& Kotani, S. (1979). Lanthionine as an essential constituent of cell wall peptidoglycan of Fusobacterium nucleatum. Curr Microbiol 3, 147-151.

Kredich, N. M. (1996). Biosynthesis of cysteine. In Escherichia coli and Salmonella typhimurium: Cellular and Molecular Biology, pp. 514-527. Edited by F. C. Neidhardt. Washington, DC: American Society for Microbiology.

Kurzban, G. P., Chu, L., Ebersole, J. L. \& Holt, S. C. (1999). Sulfhemoglobin formation in human erythrocytes by cystalysin, an L-cysteine desulfhydrase from Treponema denticola. Oral Microbiol Immunol 14, 153-164.

Li, L., Bhatia, M., Zhu, Y. Z., Zhu, Y. C., Ramnath, R. D., Wang, Z. J., Anuar, F. B., Whiteman, M., Salto-Tellez, M. \& Moore, P. K. (2005). Hydrogen sulfide is a novel mediator of lipopolysaccharide-induced inflammation in the mouse. FASEB J 19, 1196-1198.

Morhart, R. E., Mata, L. J., Sinskey, A. J. \& Harris, R. S. (1970). A microbiological and biochemical study of gingival crevice debris obtained from Guatemalan Mayan Indians. J Periodontol 41, 644-649.

Ng, W. \& Tonzetich, J. (1984). Effect of hydrogen sulfide and methyl mercaptan on the permeability of oral mucosa. J Dent Res 63, $994-$ 997.

Noji, M., Murakoshi, I. \& Saito, K. (1994). Molecular cloning of a cysteine synthase cDNA from Citrullus vulgaris (watermelon) by genetic complementation in an Escherichia coli $\mathrm{Cys}^{-}$auxotroph. $\mathrm{Mol}$ Gen Genet 244, 57-66.
Pace, C. N., Vajdos, F., Fee, L., Grimsley, G. \& Gray, T. (1995). How to measure and predict the molar absorption coefficient of a protein. Protein Sci 4, 2411-2423.

Persson, S. (1992). Hydrogen sulfide and methyl mercaptan in periodontal pockets. Oral Microbiol Immunol 7, 378-379.

Persson, S., Edlund, M. B., Claesson, R. \& Carlsson, J. (1990). The formation of hydrogen sulfide and methyl mercaptan by oral bacteria. Oral Microbiol Immunol 5, 195-201.

Pianotti, R., Lachette, S. \& Dills, S. (1986). Desulfuration of cysteine and methionine by Fusobacterium nucleatum. J Dent Res 65, 913-917.

Ratcliff, P. A. \& Johnson, P. W. (1999). The relationship between oral malodor, gingivitis, and periodontitis. A review. J Periodontol 70, 485-489.

Sambrook, J., Fritsch, E. F. \& Maniatis, T. (1989). Molecular Cloning: a Laboratory Manual, 2nd edn. Cold Spring Harbor, NY: Cold Spring Harbor Laboratory.

Schmidt, A. (1987). D-Cysteine desulfhydrase from spinach. In Methods Enzymol, pp. 449-451. Edited by W. Jakoby \& O. Griffith. New York: Academic Press.

Singh, S., Padovani, D., Leslie, R. A., Chiku, T. \& Banerjee, R. (2009). Relative contributions of cystathionine $\beta$-synthase and $\gamma$-cystathionase to $\mathrm{H}_{2} \mathrm{~S}$ biogenesis via alternative trans-sulfuration reactions. $J$ Biol Chem 284, 22457-22466.

Sirko, A. E., Zatyka, M. \& Hulanicka, M. D. (1987). Identification of the Escherichia coli cys $M$ gene encoding $O$-acetylserine sulphydrylase B by cloning with mini-Mu-lac containing a plasmid replicon. J Gen Microbiol 133, 2719-2725.

Tapuhi, Y., Schmidt, D. E., Lindner, W. \& Karger, B. L. (1981). Dansylation of amino acids for high-performance liquid chromatography analysis. Anal Biochem 115, 123-129.

Tonzetich, J. (1971). Direct gas chromatographic analysis of sulphur compounds in mouth air in man. Arch Oral Biol 16, 587-597.

Wiater, A. \& Hulanicka, D. (1979). Properties of $c y s K$ mutants of Escherichia coli K12. Acta Biochim Pol 26, 21-28.

Yaegaki, K., Qian, W., Murata, T., Imai, T., Sato, T., Tanaka, T. \& Kamoda, T. (2008). Oral malodorous compound causes apoptosis and genomic DNA damage in human gingival fibroblasts. J Periodontal Res 43, 391-399.

Yang, G., Sun, X. \& Wang, R. (2004). Hydrogen sulfide-induced apoptosis of human aorta smooth muscle cells via the activation of mitogen-activated protein kinases and caspase-3. FASEB J 18, 17821784.

Yoshida, Y., Nakano, Y., Amano, A., Yoshimura, M., Fukamachi, H., Oho, T. \& Koga, T. (2002). lcd from Streptococcus anginosus encodes a C-S lyase with $\alpha, \beta$-elimination activity that degrades L-cysteine. Microbiology 148, 3961-3970.

Yoshida, Y., Ito, S., Kamo, M., Kezuka, Y., Tamura, H., Kunimatsu, K. \& Kato, H. (2010a). Production of hydrogen sulfide by two enzymes associated with biosynthesis of homocysteine and lanthionine in Fusobacterium nucleatum subsp. nucleatum ATCC 25586. Microbiology 156, 2260-2269.

Yoshida, Y., Ito, S., Tamura, H. \& Kunimatsu, K. (2010b). Use of a novel assay to evaluate enzymes that produce hydrogen sulfide in Fusobacterium nucleatum. J Microbiol Methods 80, 313-315.

Edited by: D. Demuth 